\title{
Gallium Ga 68-labeled PSMA-11
}

National Cancer Institute

\section{Source}

National Cancer Institute. Gallium Ga 68-labeled PSMA-11. NCI Thesaurus. Code

C118961.

A radioconjug ate composed of a human prostate specific membrane antigen (PSMA)targeting ligand, Glu-urea-Lys(Ahx) (Glu-NH-CO-NH-Lys(Ahx)), conjug ated, via the acyclic radiometal chelator N,N'-bis [2-hydroxy-5-(carboxyethyl)benzyl] ethylenediamine-N,N'diacetic acid (HBED-CC), to the radioisotope gallium Ga 68, with potential use as a tracer for PSMA-expressing tumors during positron emission tomography (PET). Upon intravenous administration of the gallium Ga 68-labeled PSMA-11, the Glu-urea-Lys(Ahx) moiety targets and binds to PSMA-expressing tumor cells. Upon internalization, PSMAexpressing tumor cells can be detected during PET imaging. PSMA, a tumor-associated antigen and type II transmembrane protein, is expressed on the membrane of prostatic epithelial cells and overexpressed on prostate tumor cells. 